\title{
Recent Progress of Development of Optogenetic Implantable Neural Probes
}

\author{
Hubin Zhao \\ Biomedical Optics Research Laboratory, University College London, London WC1E 6BT, UK; \\ hubin.zhao@ucl.ac.uk; Tel.: +44-20-7679-0475
}

Received: 23 June 2017; Accepted: 8 August 2017; Published: 11 August 2017

\begin{abstract}
As a cell type-specific neuromodulation method, optogenetic technique holds remarkable potential for the realisation of advanced neuroprostheses. By genetically expressing light-sensitive proteins such as channelrhodopsin-2 (ChR2) in cell membranes, targeted neurons could be controlled by light. This new neuromodulation technique could then be applied into extensive brain networks and be utilised to provide effective therapies for neurological disorders. However, the development of novel optogenetic implants is still a key challenge in the field. The major requirements include small device dimensions, suitable spatial resolution, high safety, and strong controllability. In this paper, I present a concise review of the significant progress that has been made towards achieving a miniaturised, multifunctional, intelligent optogenetic implant. I identify the key limitations of current technologies and discuss the possible opportunities for future development.
\end{abstract}

Keywords: optogenetics; optogenetic implants; optogenetic stimulation; neural probes; implantable device

\section{Introduction}

Optogenetics is an emerging neuromodulation technique that can render neurons controllable by light. This technique combines genetic and optical methods to activate or inhibit specific neurons. Even though optogenetics is a comparatively fresh technique, using a light source to control neurons is not a brand-new idea. A very early application of optical neural stimulation was conducted in 1971 [1]. For the first time, blue light was utilised to accomplish targeted neural stimulation, and action potentials in Aplysia ganglia were successfully triggered. In 1999, Nobel laureate Francis Crick proposed the rudiment of optogenetics: a new optical method which could be used to trigger or silence specific types of neurons without any influence on other neuron populations [2]. Over the past two decades, numerous optical stimulation tools have been developed [3-8]. However, since these tools are mainly based on either the utilisation of exogenous cofactors or the expression of multiple proteins, they are difficult to be employed into in vivo applications [9]. In 2003, the expression of a single photosensitive protein, ChR2, was discovered [10]. It can be transgenically expressed into neurons, and then these neurons can be depolarised with blue light illumination [11]. After that, the new type of optogenetic technology was founded. Typically, blue light with $\sim 470 \mathrm{~nm}$ wavelength is appropriate for ChR2 activation. This light-sensitive cation channel has been employed to realise precise spatial-temporal control of neuronal activities both in vitro [11,12] and in vivo [13-17]. While ChR2 is utilised to enable neurons with specific behaviour, there is also a need to develop a different tool which can silence neurons for a particular action. In 2007, a chloride pump, halorhodopsin (HaloR, also called NpHR for Natronomas pharaonis halorhodopsin), was revealed from the archaebacterium Natronomas pharaonic [18]. This pump allows neurons to be hyperpolarised by yellow light. NpHR typically requires yellow light source with peak wavelength of $\sim 570 \mathrm{~nm}$ for activation. Then specific neuron behaviours could be inhibited with particular yellow light illuminations [18-20]. Since then, the field of optogenetics has significantly progressed. 
As a cell type-specific neuromodulation method, optogenetics opens a new door for neuroprosthesis applications. In the past decade, neuroscientists have discovered numerous light-gated microbial opsins to activate, inhibit or bi-directionally manipulate targeted neuron populations $[10,18,21,22]$. In particular, the advance of ChR2 and NpHR makes relatively low-intensity optical neuromodulation possible [21,23]. They only require less than $1 \mathrm{~mW} / \mathrm{mm}^{2}$ (ChR2) or $7 \mathrm{~mW} / \mathrm{mm}^{2}$ (NpHR) light intensity to reach the threshold. Owing to this merit, many biological experiments (in-vitro or in vivo) have been performed to investigate complex brain circuitry and chronical brain illnesses, such as Parkinson's disease [24], epilepsy [25], blindness [26], etc.

Hence, there is an increasing need to construct novel optogenetic implants, using appropriate engineering approaches. These implants should be able to achieve precise light emission, and to reliably deliver light to targeted areas of brain tissue. Besides this, they should be capable of being applied in large brain circuitries for multi-site and multi-layer operations. They should also hold reasonable spatial resolution and suitable light intensity controllability. In particular, each stimulation site should be accessed and manipulated individually. In addition, it is desirable and meaningful to integrate neural recording electronics into these implants for closed-loop neuroprosthetics. Lastly, it would be advantageous if relevant safety and durability evaluation scheme can be created for these implantable devices.

In this paper, the state of the art of optogenetic implants is reviewed. The current achievements in optogenetic implant developments are highlighted, and their limitations are also identified. Based on different methods used for light delivery, optogenetic implants can be classified into two categories: wave-guided structure and direct $\mu$ LED-on-optrode approach (optrode means optical probe). An optical waveguide is a physical component applied for light confinement and transmission [27]. A typical optical waveguide element is an optical fibre, and it has been commonly utilised for light coupling. In the $\mu$ LED-on-optrode structure, $\mu$ LEDs are selected as the light source. Rather than cooperating with waveguide elements, these $\mu$ LEDs are directly bonded on the implant and inserted into brain tissue. In the following two sections, these two groups of designs are introduced and compared, and their strengths and weaknesses are also correspondingly pointed out.

\section{Wave-Guided Structure}

\subsection{Laser-Based Optogenetic Implantable Probes}

To date, different microfabrication techniques have been explored to develop advanced implantable optical stimulators. These optical implants aim to achieve local light delivery and multi-site activation with targeted luminance intensity and spatiotemporal resolution. One of the key factors for these implants is the light source. Optogenetic implants require suitable light sources, which could possess sufficient light intensity and can precisely deliver light into particular area of the brain. The laser, as a well-developed illuminant, has been broadly applied into optrode developments. It can provide strong coherent light with low divergence $[28,29]$. This guarantees high efficiency in light delivery. For laser-based optical implants, a wave-guiding structure is essential to be utilised for light steering [28-30]. In past few years, numerous wave-guided devices have been proposed to couple with laser sources for implantable light delivery.

In 2011-2012, a glass fibre-coupled optical probe has been created by LeChasseur et al. and Dufour et al. for hybrid optical stimulation and electrical recording [31,32], as illustrated in Figure 1a. A single optical core is built into the probe for light emission, while a hollow core is utilised as the recording electrode. The optrode tip is formed with $10 \mu \mathrm{m}$ diameter, and it provides single-cell resolution for light emission. A $100 \mathrm{~nm}$ aluminum coating is incorporated to minimise optical losses during light delivery. The maximum light intensity is around $10 \mathrm{~mW} / \mathrm{mm}^{2}$. Shutters, dichroic mirrors, photomultiplier tube (PMT) detectors, and bandpass filters are incorporated to accomplish this optical-electrical microprobe system. 


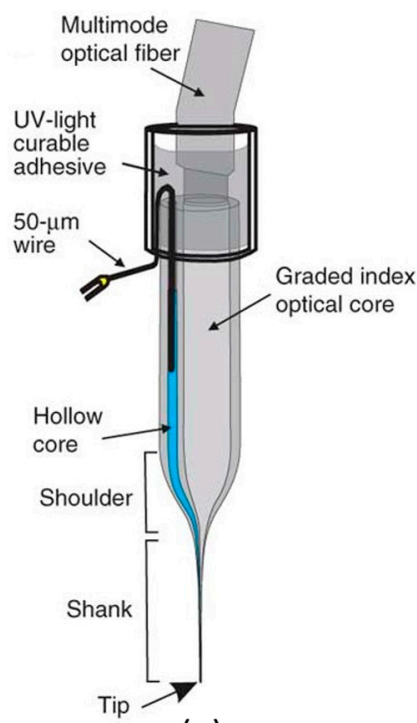

(a)

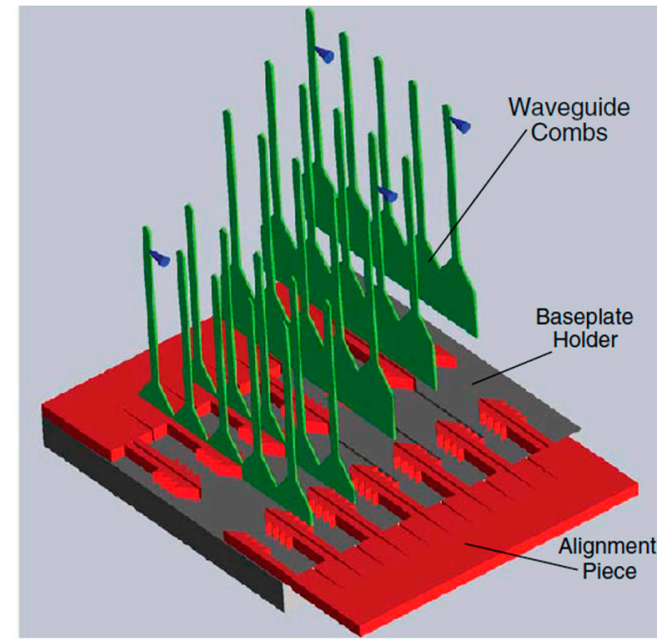

(b)

Figure 1. (a) Schematic diagram of the multimode optical fibre-coupled probe in [31]. A graded index optical core is coupled with the optical fibre to realise light delivery. A hollow core is used for the in situ observation of neural activities. The shaft tip is shaped to $10 \mu \mathrm{m}$ diameter for single-neuron manipulation. This figure is reprinted with permission from ref. [31]. (b) Picture of the 3D waveguide optical array in [33]. This figure is reprinted with permission from ref. [33].

This optical probe holds several advantages. First of all, it possesses a very small probe tip. This facilitates the manipulation of single neuron or small populations of neurons. It also minimises the damage to brain issue caused by physical implantation. Besides, it achieves closed-loop integration in a single probe. Nonetheless, due to the limited number of stimulation sites (only one for each shank), it is challenging to employ this device in a large brain area for multi-site and multi-layer stimulation. Moreover, it requires several external instruments to complete the experiment set-up, which increases the total system dimensions. This may not be ideal for freely behaving animal experiments or clinical applications.

Instead, a wave-guiding optrode-MEA (microelectrode array) system has been developed by Jing et al. for concurrent optical stimulation and electrical recording [34]. This design is constructed based on a $6 \times 6$ Utah MEA; wherein one microelectrode is substituted by a fibre-coupled optical probe. The length of each microelectrode shank is $1 \mathrm{~mm}$, and the pitch between every two microelectrodes is $400 \mu \mathrm{m}$. This optrode-MEA array achieves single site stimulation and 30-channel neural recording simultaneously, in millimetres cortical region.

This optrode-MEA array accomplishes large-region neuromodulation. Concurrent optical stimulation and electrical neural recording are obtained. However, it can only realise single-site stimulation within each $6 \times 6$ array, and multi-layer stimulation is also difficult to be achieved. In addition, the fabrication process of this device is comparatively complex, which might add difficulties for other researchers' adoptions.

In order to expand stimulation sites into multi-layers, Zorzos et al. developed a 3-dimensional waveguide-based optogenetic array [33], as displayed in Figure 1b. This design consists of multiple linear probes in which individual microwaveguides are constructed in parallel, with variable length to accomplish multi-layer stimulation. The dimensions of output apertures in each probe are $9 \mu \mathrm{m} \times 30 \mu \mathrm{m}$. In this design, a laser source from Optoengine is utilised with $1.5 \mathrm{~W}$ power; then, an average maximum light intensity of $148 \pm 56 \mathrm{~mW} / \mathrm{mm}^{2}$ is generated. External optical coupling instrument is applied to realize light coupling.

Despite the device described above has achieved 3-D multi-layer and multi-site stimulation, this design is not without concerns. First, the power consumption is over high. It will limit battery lifetime 
and device operation period. Moreover, although this waveguide structure can accomplish multi sites, it is impossible to achieve individual operation for each site. More importantly, the used coupling instrument was bulky and cumbersome, thus it is difficult to apply this device for freely-moving animal experiments and/or clinical applications.

In 2017, Schwaerzle et al. proposed a silicon-based optical probe with integrated laser diode chips [35]. This optrode consists of two identical shanks, and each shank is with $8 \mathrm{~mm}$ length, $250 \mu \mathrm{m}$ width and $50 \mu \mathrm{m}$ thickness. The dimension of the probe base are $4 \times 4 \times 0.43 \mathrm{~mm}^{3}$. Two laser diodes are bonded at the probe base to generate two stimulation sites in each shank. Each shank includes two waveguides to guide the light from probe base to the emitting facets. An averaged light intensity of $96.9 \mathrm{~mW} / \mathrm{mm}^{2}$ has been achieved. Four electrical recording sites are also constructed at each shank to accomplish simultaneous optical stimulation and electrical recording. In addition, based on this work, a dual-color probe has been developed in [36].

The work presented by Schwaerzle et al. prevents using bulky and cumbersome coupling instruments. Moreover, it achieves multi-site stimulation and in situ electrical recording. However, there is still some room to improve the spatial resolution of stimulation sites (currently only two on each shank). In addition, silicon is a relatively fragile material as probe substrate, the safety and long-term durability of the probe need to be carefully considered.

\subsection{LED-Based Optogenetic Implantable Probes}

Regarding the wave-guiding devices mentioned above, another concern is the laser light source. Even though laser systems can provide coherent light delivery with low divergence, there are still some areas to be improved, in terms of system miniaturisation, power efficiency, illumination stability, and operation warm-up period [28-30]. Additionally, laser systems usually require a dedicated optical interface for practical use [28,29]. This may add extra restrictions on the freedom of experimental subjects. Another type of light source used for optogenetic stimulation is the $\mu$ LED. $\mu$ LEDs could potentially provide more stable light emission. Some $\mu$ LEDs could also hold faster light-switching speeds with lower power consumption [28,37]. Moreover, most $\mu$ LEDs are compatible with conventional electronics for $\mu$ LED driving and communication [28,29].

Therefore, wave-guided $\mu$ LED-based optical probes have drawn increasing attraction among neural-engineers. In 2012, an optical fibre-coupled multi-diode array has been developed by Stark et al. [38]. This array consists of six individual $\mu$ LED-fibre coupled assemblies. The total length of the optical fibre is up to $50 \mathrm{~mm}$, containing four stepped sections. The last section is $5 \mathrm{~mm}$ long with a $60-70 \mu \mathrm{m}$ diameter. A cone-shape tip is constructed with $\sim 12^{\circ}$ at the end of the shank. A schematic diagram is shown in Figure 2a. This single fibre assembly is duplicated six times, to construct an optical array for multi-neuron operations.

This fibre-coupled optical array achieves multi-site stimulation by assembling six individual probes. Besides, it also realises adjustable-depth stimulation, as the four-step probe has high flexibility for stimulation depth. However, it does not achieve multi-site/multi-layer stimulation within a single probe. In addition, the system dimensions are relatively large. Both factors could be the bottlenecks for the use of this optical array for widespread applications.

Similarly, in 2014, another fibre-coupled $\mu$ LED-based optical probe has been fabricated by Schwaerzle et al. [39], and the system overview is displayed in Figure $2 b$. The $\mu$ LED is flip-chip bonded on a polyimide (PI) ribbon cable. The PI cable is bendable, ensuring the flexibility of the overall system. A silicon ( $\mathrm{Si}$ ) housing is implemented to adhere the $\mu \mathrm{LED}$ to the PI cable. A $5 \mathrm{~mm}$-long optical fibre is fixed into a predefined recess of the $\mathrm{Si}$ housing to complete the system.

This wave-guiding $\mu$ LED-based optrode can deliver light into deep tissue areas, with the incorporation of an optical fibre. It achieves $1.71 \mathrm{~mW} / \mathrm{mm}^{2}$ light intensity with a $30 \mathrm{~mA}$ driving current and a $10 \%$ duty cycle. This meets the requirements of the ChR2 activation threshold (less than $1 \mathrm{~mW} / \mathrm{mm}^{2}$ ). Additionally, it utilises relatively straightforward fabrication techniques, which could be adapted by other researchers. However, due to the utilisation of the bulky optical fibre, it 
would be challenging to multiplex this optrode for multi-site operations. Besides, although the light intensity reached the ChR2 activation threshold, it may be insufficient for higher-intensity stimulation. In addition, in order to achieve this $1.71 \mathrm{~mW} / \mathrm{mm}^{2}$ light intensity, the consumed power is very high.

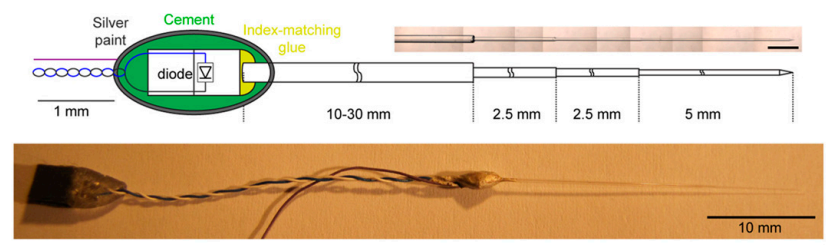

(a)

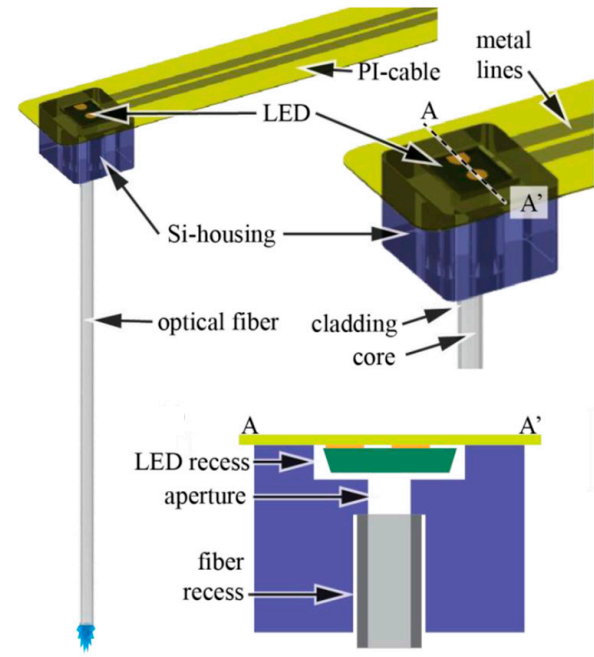

(b)

Figure 2. (a) Fibre-coupled multi-diode optical array in [38]. A single four-step fibre probe. The total length is $50 \mathrm{~mm}$, and the last shank is $5 \mathrm{~mm}$ long with a $12^{\circ}$ tip. This figure is reprinted with permission from ref. [38]. (b) Cartoon image of the fibre-coupled $\mu$ LED optical probe [39]. This system mainly consists of a $270 \times 220 \times 50 \mu \mathrm{m}^{3}$ LED chip, a flexible PI cable, a $550 \times 500 \times 380 \mu \mathrm{m}^{3}$ Si housing, and a $5 \mathrm{~mm}$-long optical fibre with $125 \mu \mathrm{m}$ diameter. This figure is reprinted with permission from ref. [39].

Based on the work presented in [39], in 2015, Schwaerzle et al. developed a $3 \times 3 \mu$ LED fibre array for multi-site stimulation [40]. Although the design in [40] is more advanced, it has very similar limitations with the probe previously developed in [39].

Apart from all the devices described above, other fabrication technologies have also been explored, and diverse wave-guiding structures (both laser-coupled and LED-coupled) have been developed [41-43]. A performance summary of recently published wave-guided optogenetic implants is presented in Table 1. Even though these devices can meet the requirements of implantable optogenetic applications to some degree, they are still with some concerns. One limitation of some devices is that only one stimulation site could be constructed along the single probe shaft, which are not capable to be utilised for dispersed targets. In particular, due to comparatively bulky dimensions of some wave-guiding structures, the solitary light source is strenuous to be multiplexed for multi-site stimulations. For some other devices, although the single probe is duplicated into the array configuration to accomplish multi-site operations, the stimulation depth is still fixed, and multi-layer stimulation is not reachable within the single probe. This could potentially limit their applications in 3D brain network. Moreover, the light coupling efficiency of wave-guiding structures would be another limitation. Particularly for the $\mu$ LED-fibre coupling efficiency, the maximum value is less than $10 \%[28,44]$. This may increase the system power budget and reduce the light emission efficiency. In addition, more importantly, due to the incorporations of bulky wave-guiding structures and external optical communicators, these devices might be challenging to be applied into freely-moving animal experiments and/or clinical applications. 
Table 1. Performance summary of recently published wave-guiding structure based optogenetic implants.

\begin{tabular}{|c|c|c|c|c|c|c|c|c|c|}
\hline Ref./Year & $\begin{array}{c}\text { Light } \\
\text { Source/Wavelength }\end{array}$ & Dimensions & $\begin{array}{l}\text { No. of Sti } \\
\text { Sites }\end{array}$ & $\begin{array}{l}\text { Max Light } \\
\text { Intensity }\end{array}$ & $\begin{array}{l}\text { Max Power } \\
\text { Consumption }\end{array}$ & $\begin{array}{l}\text { Max Pulse } \\
\text { Frequency }\end{array}$ & $\begin{array}{l}\text { Electrical } \\
\text { Recording }\end{array}$ & Fabrication Process & $\begin{array}{l}\text { Substrate } \\
\text { Material }\end{array}$ \\
\hline$[31] / 2011$ & Laser/488 nm & $\begin{array}{c}\text { Diameter: } 200 \mu \mathrm{m} ; \\
\text { Shaft tip diameter: } 10 \mu \mathrm{m}\end{array}$ & 1 & $10 \mathrm{~mW} / \mathrm{mm}^{2}$ & - & - & Yes & Custom-Fabricated & - \\
\hline [34]/2012 & Laser/473 nm & Shaft length (L): $1 \mathrm{~mm}$; Spacing: $400 \mu \mathrm{m}$ & 1 & $5 \mathrm{~mW} / \mathrm{mm}^{2}$ & - & $40 \mathrm{kHz}$ & Yes & Custom-Fabricated & - \\
\hline [33]/2012 & Laser/473 nm & Apertures: $9 \mu \mathrm{m} \times 30 \mu \mathrm{m}$ & $1 \times 25$ & $148 \pm 56 \mathrm{~mW} / \mathrm{mm}^{2}$ & $1500 \mathrm{~mW}$ & - & No & Custom-Fabricated & Silicon \\
\hline$[35] / 2017$ & Laser/650 nm & $\begin{array}{l}\text { Shaft L: } 8 \mathrm{~mm} \text {; W: } 250 \mu \mathrm{m} \text {; laser diode } \\
\text { dimensions: } 300 \times 300 \times 100 \mu \mathrm{m}^{3}\end{array}$ & $2 \times 2$ & $96.9 \mathrm{~mW} / \mathrm{mm}^{2}$ & $12.82 \mathrm{~mW}$ & $100 \mathrm{kHz}$ & Yes & Custom-Fabricated & Silicon \\
\hline$[41] / 2011$ & Laser/473 nm, $593 \mathrm{~nm}$ & Shaft length: $7 \mathrm{~mm}$; Width: $200 \mu \mathrm{m}$ & 1 & - & $\begin{array}{c}21 \mathrm{~mW} \\
\text { (for blue light) }\end{array}$ & - & Yes & Custom-Fabricated & Polyimide \\
\hline [42]/2013 & Laser/473 nm & Shaft length: $5 \mathrm{~mm}$; Width: $200 \mu \mathrm{m}$ & 1 & $9400 \mathrm{~mW} / \mathrm{mm}^{2}$ & $50 \mathrm{~mW}$ & $25 \mathrm{~Hz}$ & Yes & Custom-Fabricated & Silicon \\
\hline [43]/2015 & Laser/473 nm & Diameter: $150 \mu \mathrm{m}$ & 1 & $\begin{array}{c}0.9 \mathrm{~mW} \\
\left(\sim 51 \mathrm{~mW} / \mathrm{mm}^{2}\right)\end{array}$ & - & - & Yes & Custom-Fabricated & Silicon \\
\hline$[38] / 2012$ & $\mu \mathrm{LED} / 470,589,639 \mathrm{~nm}$ & $\begin{array}{l}\text { Shaft L: } 5 \mathrm{~mm} \text {; Diameter: } 60-70 \mu \mathrm{m} \\
\text { (Blue) } \mu \text { LED dimensions: } 1.6 \times 0.6 \mathrm{~mm}^{2}\end{array}$ & $1 \times 6$ & $\begin{array}{l}40 \mathrm{~mW} / \mathrm{mm}^{2} \\
\text { (blue light) }\end{array}$ & $\begin{array}{l}\text { Current: } \\
60 \mathrm{~mA}\end{array}$ & - & No & Custom-Fabricated & - \\
\hline [39]/2014 & $\mu \mathrm{LED} / 460 \mathrm{~nm}$ & $\begin{array}{l}\text { Total length: } 5 \mathrm{~mm} \text {; Diameter: } 125 \mu \mathrm{m} ; \\
\text { } \text {;EED dimensions: } 270 \times 220 \times 50 \mu \mathrm{m}^{3}\end{array}$ & 1 & $1.71 \mathrm{~mW} / \mathrm{mm}^{2}$ & $\begin{array}{l}\text { Current: } \\
30 \mathrm{~mA}\end{array}$ & - & No & Custom-Fabricated & Polyimide \\
\hline$[40] / 2015$ & $\mu \mathrm{LED} / 460 \mathrm{~nm}$ & $\begin{array}{l}\text { Total length: } 5 \mathrm{~mm} \text {; Diameter: } 125 \mu \mathrm{m} ; \\
\mu \text { LED dimensions: } 270 \times 220 \times 50 \mu \mathrm{m}^{3}\end{array}$ & $1 \times 9$ & $1.28 \mathrm{~mW} / \mathrm{mm}^{2}$ & $\begin{array}{l}\text { Current: } \\
30 \mathrm{~mA}\end{array}$ & - & No & Custom-Fabricated & Polyimide \\
\hline
\end{tabular}




\section{3. $\mu$ LED-on-Optrode Structure}

In addition to wave-guiding devices, another type of optogenetic implants relies on the $\mu L E D$-on-Optrode structure. In this type of structure, $\mu$ LEDs are straight bonded onto optical probes and distributed along the probe shaft. Then they are directly inserted into the targeted area of brain tissue. This strategy can provide higher light emission efficiency, and has the potential to realise multi-site/multi-layer stimulation within a single integral optrode. It could also free subjects from the movement restrictions caused by some bulky and cumbersome wave-guiding components. For instance, a flexible polyimide based integrated $\mu$ LED optrode has been constructed by Cao et al. [45], as demonstrated in Figure 3a. In this optrode, one stimulation site is created at the probe tip, surrounded by three electrode recording sites. This optical-electrical hybrid design achieves optogenetic stimulation and simultaneous neural recording within a single probe. The whole shaft length is $12 \mathrm{~mm}$, and the total width is $900 \mu \mathrm{m}$. An off-the-shelf $\mu$ LED is utilised as the light emitter, with dimensions of $1000 \times 200 \times 600 \mu \mathrm{m}^{3}$. The $\mu \mathrm{LED}$ drive voltage is $2.9 \mathrm{~V}$, and the drive current is $5 \mathrm{~mA}$. The light intensity of the $\mu \mathrm{LED}$ is fixed at $0.7 \mathrm{~mW} / \mathrm{mm}^{2}$.

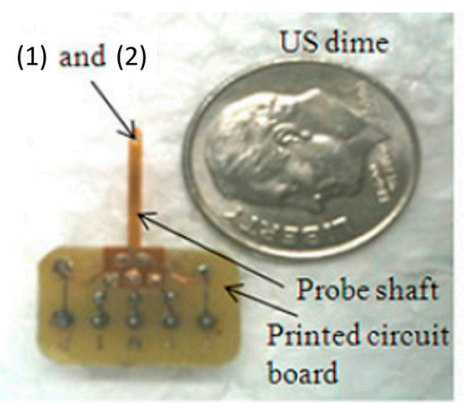

(1)

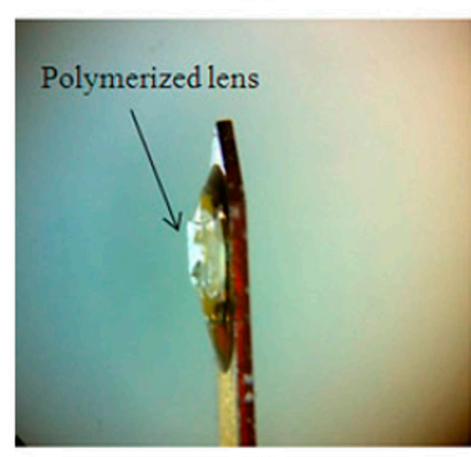

(3)

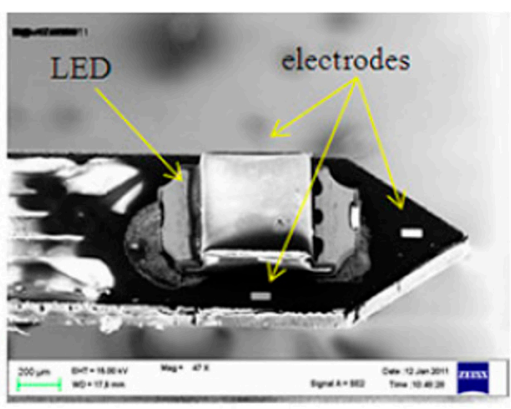

(2)

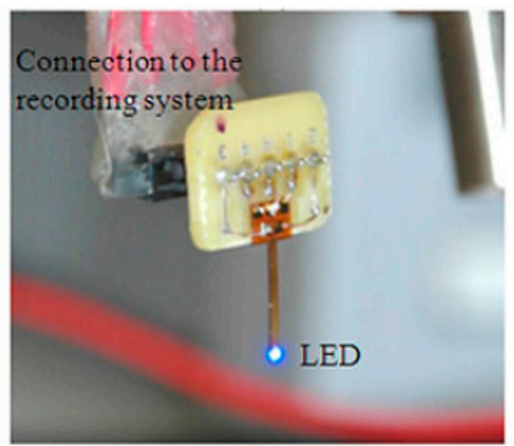

(4) (a)

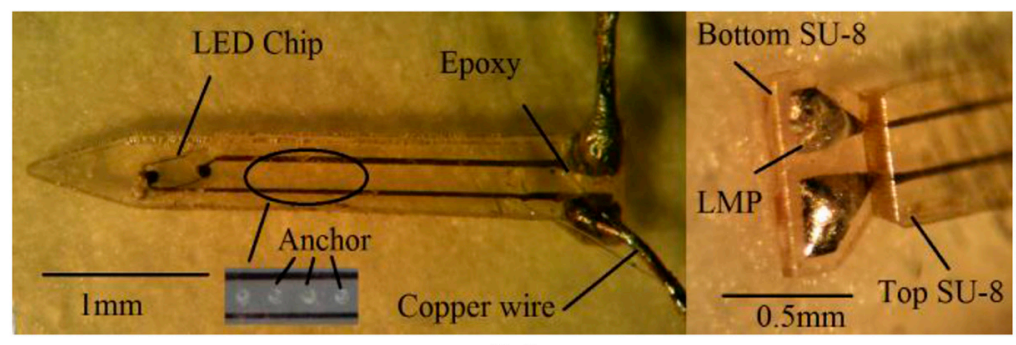

(b)

Figure 3. Cont. 

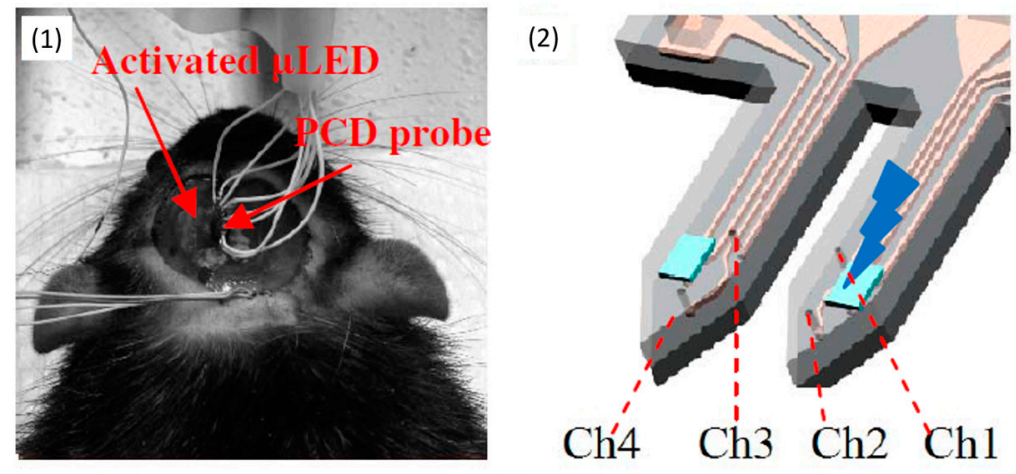

(c)

Figure 3. (a) Flexible polyimide-based $\mu$ LED optrode in [45]. (1) A printed circuit board (PCB) is fabricated to assemble the optrode. (2) A scanning electron microscope (SEM) image of the optrode tip. The $\mu$ LED site is bonded along with three recording sites. (3) A polymerised lens is covered on the $\mu$ LED. (4) The overall system. $\mu$ LED is turned on by a $2.9 \mathrm{~V}$ forward bias voltage. This figure is reprinted with permission from ref. [45]. (b) Samsung $\mu$ LED mounted at the tip of the fabricated optrode in [46]. Several SU-8 anchors are created along the probe shaft, enhancing the bonding strength of two SU-8 layers. Cooper wire is bonded on the probe via the low melting point (LMP). Epoxy is adopted to further strengthen the bonding robustness. This figure is reprinted with permission from ref. [46]. (c) The PCD-based optical probe in $[47,48]$. (1) This PCD probe is inserted into an experimental rat for the in-vivo test. (2) A diagram of this two-shank probe. In each shank, the $\mu$ LED is placed at the shaft tip, and two recording channels are positioned in the vicinity of stimulation site. This figure is reprinted with permission from ref. [48].

This integrated $\mu L E D$ optrode accomplishes both optical stimulation and electrical recording. Compared to wave-guided optrodes, it is more convenient for closed-loop integration. Besides, it requires less power budget and held better compactness. Nevertheless, there are several considerations for this design. Firstly, the $\mu$ LED is too bulky. This would be a bottleneck both for realising multiple stimulation sites and minimising optrode dimensions. Furthermore, heating is a key concern with the $\mu$ LED-on-optrode structure, but this design does not take $\mu$ LED thermal effects into account. This may potentially induce over-heating in brain tissue. Also, this design requires $14.5 \mathrm{~mW}$ power to achieve $0.7 \mathrm{~mW} / \mathrm{mm}^{2}$ light intensity, and so that the power efficiency has some spaces for enhancement. Furthermore, the generated light intensity is difficult to activate the ChR2, whose activation threshold is $\sim 1 \mathrm{~mW} / \mathrm{mm}^{2}$. In addition, the optrode shaft is too long, being much longer than the average cortex thickness [49]. It may need to be shortened in the future. Moreover, the optrode width of $900 \mu \mathrm{m}$ might damage tissue and cause neuro-inflammatory responses.

At the same period, a two-layer SU-8 based optrode has been proposed by Fan et al. [46], and the fabricated optical probe is displayed in Figure $3 \mathrm{~b}$. The total length of the probe is $4.2 \mathrm{~mm}$, and the width is $0.86 \mathrm{~mm}$. The $\mu \mathrm{LED}$ (form Samsung Inc., Seoul, Korea) has dimensions of $550 \times 600 \times 200 \mu \mathrm{m}^{3}$. A single stimulation site is formed at the optrode tip. The working threshold of this $\mu$ LED is $2.6 \mathrm{~V}$, and typical forward bias voltages are $3.0 \mathrm{~V}, 3.2 \mathrm{~V}$, and $3.4 \mathrm{~V}$. Corresponding drive currents and power consumptions are $11.2 \mathrm{~mA} / 33.6 \mathrm{~mW}, 22.6 \mathrm{~mA} / 72.4 \mathrm{~mW}$, and $38.2 \mathrm{~mA} / 130 \mathrm{~mW}$. The maximum voltage is $3.6 \mathrm{~V}$, generating drive current more than $60 \mathrm{~mA}$ (power consumption $>216 \mathrm{~mW}$ ). When the $\mu \mathrm{LED}$ is biased with $3.4 \mathrm{~V}$, the light intensity is around $0.9 \mathrm{~mW} / \mathrm{mm}^{2}$; when the bias voltage is increased to $3.6 \mathrm{~V}$, the light intensity would be approximately equal to $0.95 \mathrm{~mW} / \mathrm{mm}^{2}$. If limiting the bias voltage to $2.74 \mathrm{~V}$ and constraining total power to $7 \mathrm{~mW}$, the local temperature increase is restricted to $0.5^{\circ} \mathrm{C}$.

The SU-8 has outstanding flexibility, and this could decrease the tissue damage due to implantation. Also, this type of material is comparatively easy to fabricate. However, this SU-8 optrode is still with some concerns. Firstly, similar to the optrode previously mentioned (Figure 3a), the bonded $\mu \mathrm{LED}$ is large, which is not suitable for multi-site stimulation. Secondly, the light intensity 
generated is not strong enough. Only when the $\mu$ LED is biased with $3.6 \mathrm{~V}$ voltage, it could nearly meet the ChR2 activation threshold. Higher light intensity is therefore required. Moreover, the power consumption/efficiency may need to be enhanced. Given $3.4 \mathrm{~V}$ and $3.6 \mathrm{~V}$ drive voltages, power consumption levels are $130 \mathrm{~mW}$ and $216 \mathrm{~mW}$ respectively. This may not be ideal for long-term implantable applications. In addition, although the thermal increment is limited to $0.5^{\circ} \mathrm{C}$ with an input voltage of $2.74 \mathrm{~V}$, thermal effects might need to be carefully investigated when the $\mu$ LED is biased with the input voltages higher than $3.0 \mathrm{~V}$.

Based on this SU-8 optrode, an improved work has been conducted by Fan et al. in $[47,48]$. Instead of using SU-8, a polycrystalline diamond (PCD) substrate has been constructed to obtain an integrated optical-electrical probe, as shown in Figure 3c. This optrode design has two different versions: single-shank and two-shank. For the two shank version, there are one $\mu$ LED site and two microelectrodes on each shank, achieving optical stimulation and electrical recording; there is one more recording site on the shank. The same $\mu$ LED as above (Figure $3 b$ ) is utilised. The length of each shank is $5 \mathrm{~mm}$, and the width is $0.9 \mathrm{~mm}$. The total dimensions of both versions of probes are $7.38 \mathrm{~mm} \times 6.5 \mathrm{~mm} \times 0.25 \mathrm{~mm}$. The typical applied voltages are same to the previous work in [46], with light intensities of $0.6 \mathrm{~mW} / \mathrm{mm}^{2}, 1 \mathrm{~mW} / \mathrm{mm}^{2}$ and $1.5 \mathrm{~mW} / \mathrm{mm}^{2}$. In particular, due to the excellent thermal conductivity of PCD (up to $1800 \mathrm{Wm}^{-1} \mathrm{~K}^{-1}$ ), this optrode demonstrates outstanding heat dissipation performance. When the optrode is under $100 \mathrm{~ms}$ stimulation with $1 \mathrm{~Hz}$ pulses, the thermal increment is consistently below $1^{\circ} \mathrm{C}$.

However, although the PCD-based probe exhibits excellent thermal dissipation performance, there are still several points need to be considered. First of all, the light intensity produced is not fully sufficient for ChR2 activation. Only with a bias voltage of $3.6 \mathrm{~V}$ the ChR2 threshold could be triggered. A powerful light-driving ability is thus needed. Besides, the $0.9 \mathrm{~mm}$ shaft width of the probe is still over-wide, which may be likely to result in tissue injury and subsequent infection. In addition, the $\mu$ LED dimensions are still a limitation for multi-site stimulation and optrode miniaturisation.

Rather than employing commercially available $\mu$ LEDs, a sapphire-based optical probe with custom-designed GaN $\mu$ LEDs has been developed by McAlinden et al. [50], as shown in Figure 4a. The total length of this optrode is $7 \mathrm{~mm}$, with a $1 \mathrm{~mm}$-long shaft. The width of the optrode shaft is defined as $80 \mu \mathrm{m}$, to diminish the tissue damage caused by physical implantation. Five GaN $\mu$ LEDs are evenly distributed along the shaft with $250 \mu \mathrm{m}$ spacing. The diameter of each $\mu$ LED is $40 \mu \mathrm{m}$. Six bonding pads are constructed on the optrode head. Five of these are anode pads with other a common cathode terminal. This configuration allows each $\mu$ LED to be individually controlled. The maximum radiance intensity of this probe is $600 \mathrm{~mW} / \mathrm{mm}^{2}$, and the maximum temperature increment is limited to $\sim 1.5^{\circ} \mathrm{C}$.

This optrode accomplishes multi-site/multi-layer stimulation by applying the direct $\mu \mathrm{LED}-o n-o p t r o d e ~ s t r u c t u r e$. It obtains strong light intensity with a reasonable temperature increase. Nevertheless, there are still several considerations with this design. Firstly, the high material rigidity of sapphire may lead to tissue damage during or after insertion. Furthermore, the biocompatibility of both sapphire and $\mathrm{GaN}$ is a concern, so that further tissue infection might be caused. Besides this, due to the narrow shaft $(80 \mu \mathrm{m})$, the future integration of neural recording electrodes would be problematic, which may prevent this device from being applied to closed-loop applications.

Based on the work illustrated in Figure 4a, an improved work has been completed in 2016 by Scharf et al. [51]. Instead of using sapphire, silicon is utilised to construct the substrate. An image of this silicon-based neural probe is shown in Figure $4 \mathrm{~b}$. This design consists of six optical shanks. Each shank includes sixteen GaN $\mu$ LEDs along a $750 \mu \mathrm{m}$-long probe shaft. By incorporating ninety-six $\mu L E D s$, this 6-shank optrode provides high-density stimulations. It demonstrates outstanding spatial resolution, and is also able to generate sufficiently strong light intensity $\left(\sim 400 \mathrm{~mW} / \mathrm{mm}^{2}\right)$. A dedicated integrated circuit (IC) PCB is incorporated to control the probe, and each $\mu$ LED can be individually addressed. Additionally, based on simulation results, with $150 \mathrm{~mW} / \mathrm{mm}^{2}$ luminous intensity and $50 \mathrm{~ms}$ operation duration, the surface temperature increases by $\sim 0.5^{\circ} \mathrm{C}$ on average. 


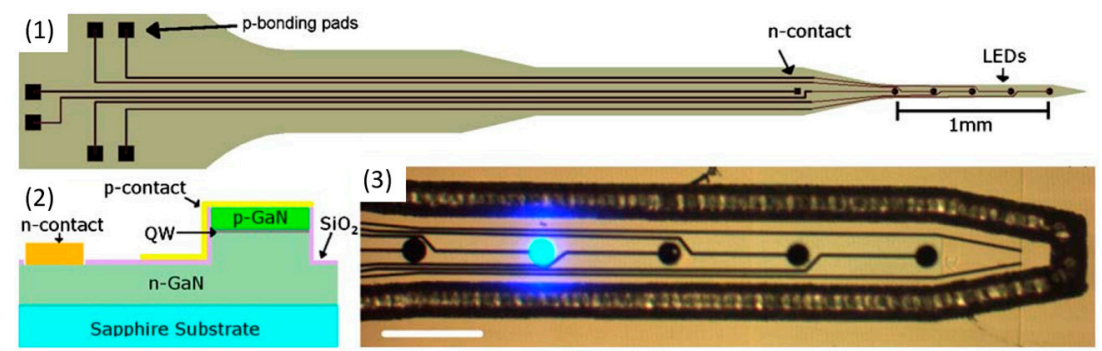

(a)
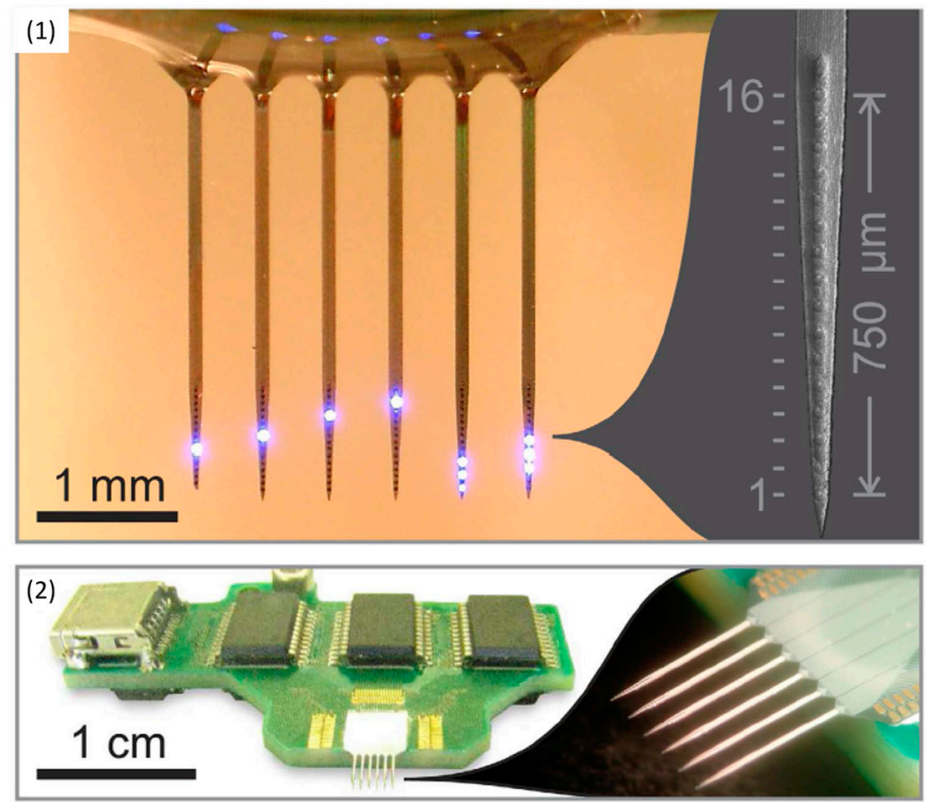

(b)

Figure 4. (a) Sapphire-based GaN $\mu L E D$ optrode in [50]. (1) System architecture of this optrode. Six bonding pads are placed at the head part to control corresponding $\mu$ LEDs which are uniformly positioned along the optrode shaft. (2) The cross-section view of the fabrication process. (3) The optrode shaft including five $\mu$ LEDs, one of them turned on with bright light. This figure is reprinted with permission from ref. [50]. (b) Silicon-based 6-shank GaN $\mu$ LED optrode in [51]. (1) 16 stimulation sites are created on each shank, and they are uniformly distributed along the $750 \mu \mathrm{m}$ shaft. Every $\mu \mathrm{LED}$ can be individually manipulated. (2) System diagram. The fabricated optrode is bonded on a dedicated control PCB. This figure is reprinted with permission from ref. [51].

This brand-new optical probe has demonstrated several merits, such as high spatial resolution, strong radiance, reasonable thermal effects and the controllability/compatibility with conventional microelectronics. Even so, there are still some areas which may need to be improved. First of all, although this design demonstrates a reasonable thermal effects, these results are based only on simulation with a predefined light intensity, short operation duration and low repetition rate. It is desirable to analyse the thermal dissipation performance experimentally. In particular, even though in simulation only, the peak increment of temperature is around $4{ }^{\circ} \mathrm{C}$. In actual use, this would be more severe if either the irradiance, working time and/or operation frequency are increased. Moreover, although the authors claims that recording electrodes could be potentially integrated into this system in the future, this might be challenging due to the narrow optrode tip and tight $\mu$ LED spacing. Besides, for implantable applications, the PCB control board is relatively bulky and heavy. In addition, despite silicon being comparatively inert, biocompatibility with brain tissue may still need to be taken into account.

At the same period, Wu et al. proposed another type of high-resolution silicon-based optrode [52]. The optrode consists of four shanks, with three stimulation sites ( $\mu$ LED: $10 \mu \mathrm{m} \times 15 \mu \mathrm{m})$ and 
eight recording sites $(11 \mu \mathrm{m} \times 13 \mu \mathrm{m})$. The shaft length is $5 \mathrm{~mm}$, and shaft width is only $70 \mu \mathrm{m}$. With $13 \mathrm{~mA}$ input current, a light intensity of $353 \mathrm{~mW} / \mathrm{mm}^{2}$ is produced. Moreover, each stimulation site can be individually controlled by external PCB control board. This silicon-based optrode achieves high-resolution, high-intensity, multi-layer stimulation. However, this design has similar limitations with the work presented in [51]: no experimental thermal analysis, bulky external PCB control board, and concerns about biocompatibility and long-term durability of silicon substrate.

In contrast, a more advanced multifunctional injectable probe has been created based on flexible microelectronics by Kim et al. [53], as illustrated in Figure 5a. This design transforms the conventional solid optrode substrate into a flexible polymer base. Moreover, it integrates different material layers to achieve multiple functions, including electrical recording (Layer 1), optical detection (Layer 2), optical stimulation (Layer 3), and thermal sensing (Layer 4). In particular, a releasable base is built into this probe. During implantation, this injectable $\mu$ needle leads all of the functional layers into the targeted tissue region. After insertion, the $\mu$ needle is removed using dissolving fluid, and only the functional components are kept in the subject brain. The total thickness of all injected layers is only $\sim 20 \mu \mathrm{m}$, which will greatly minimise any tissue damage induced by device insertion. The maximum light intensity is $\sim 40 \mathrm{~mW} / \mathrm{mm}^{2}$, which is sufficient for opsins activation. If the light intensity is limited to $17.7 \mathrm{~mW} / \mathrm{mm}^{2}$, the temperature increase is restricted to $1{ }^{\circ} \mathrm{C}$. Additionally, this device is compatible with wireless power transmitter, which could be highly beneficial for the freely-moving animal experiments.
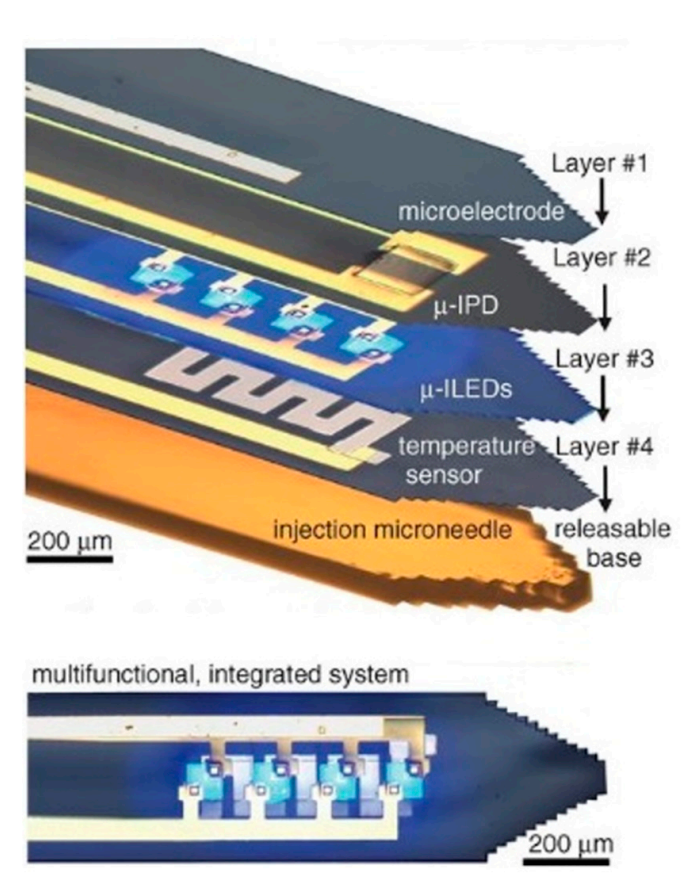

(a)

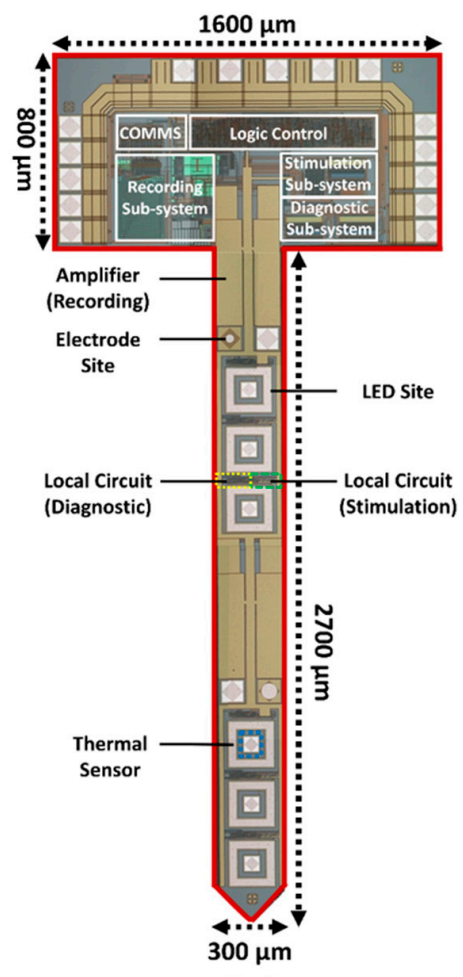

(b)

Figure 5. (a) Flexible electronics-based multifunctional implantable probe in [53]. Four different functional layers are incorporated along with a releasable base. The recording microelectrode is constructed on Layer 1; and then a micro-inorganic photodetector ( $\mu$ IPD) is utilised for photodetection at Layer 2; Layer 3 contains four micro-inorganic LEDs ( $\mu$-ILEDs) for optogenetic stimulation; and Layer 4 is dedicated to temperature sensing. This figure is reprinted with permission from ref. [53]. (b) CMOS-based active multifunctional optogenetic implant in [54]. Six stimulation sites are placed along the optrode shaft to be individually controlled. Self-diagnostic scheme is built into each site to enhance system safety and reliability. In situ recording electronics and thermal sensor are also accomplished at each site. 
This multifunctional implantable probe combines an optogenetic stimulator, recording electrode, photo detector, and temperature sensor in an integral device. It demonstrates excellent properties compared to the other devices reviewed above. Nonetheless, several concerns have been still identified and may need to be addressed in the future. One concern is the system thermal effect. The overall temperature increase can be limited to $1^{\circ} \mathrm{C}$, but this is on the condition of $17.7 \mathrm{~mW} / \mathrm{mm}^{2}$ radiance. Given continuous $23.5 \mathrm{~mW} / \mathrm{mm}^{2}$ light power, the temperature rise would reach $10^{\circ} \mathrm{C}$. Also, these thermal analysis results are obtained on the condition that the device is only implanted at a depth of $0.3 \mathrm{~mm}$ into the brain of the subject. The thermal increment would be higher with further insertion. Both the above situations may potentially cause thermal damage to the brain tissue. Another concern is its relatively low light intensity. This device is able to achieve a maximum light intensity of $40 \mathrm{~mW} / \mathrm{mm}^{2}$. Although this value is much higher than the ChR2 activation threshold, it may not be sufficient for high-intensity deep-penetration applications. Moreover, under wireless control mode, only $7 \mathrm{~mW} / \mathrm{mm}^{2}$ radiance is generated using $4.08 \mathrm{~mW}$ input electrical power. This indicates that the power efficiency still has some room for enhancement. Furthermore, the total length of the probe shaft is less than $1 \mathrm{~mm}$, and this would become problematic for neural stimulation in deeper cortex areas. Besides, the construction of this multifunctional optrode relies on a costly and complicated custom-fabrication flow, which may result in restrictions for other researchers' adoption. In addition, due to the system complexity, utilising a conventional microelectronic device to conduct logic control and two-way communication with the implant might be another challenge. Finally, operational degradation, such as electronic failure or mechanical breakage, might also need to be carefully considered.

Between 2014 and 2017, Zhao et al. utilised conventional commercially-available CMOS (Complementary Metal-Oxide-Semiconductor) process to develop a novel active intelligent optogenetic implant [54-56], as displayed in Figure 5b. A closed-loop version of the proposed optrode is constructed and fabricated using a $0.35-\mu \mathrm{m}$ CMOS process. Six stimulation sites have been constructed and placed along the optrode shaft to realise multichannel neural stimulation. The maximum light intensity is $1256 \mathrm{~mW} / \mathrm{mm}^{2}$, with a total power consumption of $6.04 \mathrm{~mW}$ when six LED sites are all on. An intensity magnitude control scheme is created which can adjust the LED drive current in different 256 levels. This provides an outstanding luminance controllability and ensures more accurate light delivery. This intensity magnitude control strategy could also minimise the over-heating hazard, confining the light power into a reasonable working range. Besides, the pulse width modulation mechanism is also implemented in this optrode design along with the intensity magnitude modulation, so as to attain satisfactory overall intensity modulations. More importantly, a self-diagnosis function is developed to monitor the optrode working status in real-time. If any abnormality occurs, either substrate breakage or $\mu \mathrm{LED}$ bonding erosion, it can be observed by the diagnostic sensing circuitry. Based on different scenarios, this will let user/clinical technician decide whether to switch to a backup $\mu$ LED or to entirely turn off the implant. This self-diagnosis strategy profoundly enhances the functioning reliability and operational safety of the proposed optrode. In addition, an in situ resistor-based temperature sensor is developed to monitor the heating effect of the light emitters. These thermal sensors are placed within $\mu$ LED pads, observing the real-time temperature on site. This thermal sensing design significantly heightens system robustness and, more importantly, makes sure of safe operation in brain tissue. Furthermore, electrical neural recording circuitry is incorporated into this implant. This can observe concurrent local neural signals while the targeted neuron populations are photosensitized by the optical stimulator. By employing the recording subsystem, a closed-loop neural interface is completed. This neural processing platform could be widely utilised for diverse neurological disorders, such as Parkinson's disease and epilepsy.

The work described above is the first CMOS-based active optogenetic implant, but there are also some challenges within this device. First, this device requires relatively complicated post-processing to cut out the T-shape optrode. Moreover, CMOS technology is based on silicon substrate, but silicon is comparatively fragile, which may influence the longevity of the device. At last, although temperature sensors are incorporated into this system, the generated heat by LEDs might still be a concern. 
Based on the literature survey conducted above, a performance summary of recently published

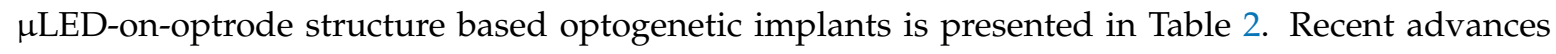
in $\mu$ LED-on-optrode devices provide the feasibility to directly interact with deep brain tissues via optrodes. However, although these devices can achieve direct light delivery for optogenetic stimulation, their performances could still be enhanced from different aspects. Some devices could only obtain relatively weak light emission, which would be challenging for ChR2 (or other opsins) activations. Some devices can generate sufficient luminance, but they lack appropriate intensity modulation methods. Moreover, a very critical concern for implantable applications is safety. In particular, substrate integrity and operational degradation of light emitters are two dominant factors, which need to be taken into consideration. Besides, thermal dissipation is always a major concern for

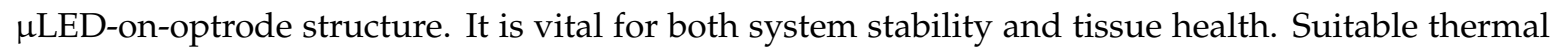
management is demanded, and temperature sensing circuitry is required to be integrated into the implant. Furthermore, electrical neural recording circuitry is desirable to be imported into the optogenetic implants, realising closed-loop integration. Some optical implants have incorporated recording electronics, but they use separate fabrication processes and/or control electronics from those used for the optical stimulators. This might increase the design and fabrication complexities, and cause difficulties for system integration. In addition, most of the current devices have been custom-fabricated. This might require comparatively huge financial and labour resources, and, more importantly, restrict their broader adoptions. Most importantly, except [54-56], all of these devices are controlled by external instruments/electronic systems. There are no active implantable electronics built inside to internally control the implants. All functions such as optical stimulation, electrical recording, and thermal sensing are performed via passive drive/control electronics. This may lead to a heavyweight for the overall system, and add obstacles for freely-moving animal experiments and clinical trials. Besides, their external control electronics are mostly not fully compatible with conventional biomedical microprocessors, which might limit their widespread applications. 
Table 2. Performance summary of recently published $\mu$ LED-on-optrode structure based optogenetic implants.

\begin{tabular}{|c|c|c|c|c|c|c|c|c|c|c|}
\hline Ref./Year & Dimensions & $\begin{array}{l}\text { No. of } \\
\text { Sti Sites }\end{array}$ & $\begin{array}{l}\text { Max Light } \\
\text { Intensity }\end{array}$ & Max Power & $\begin{array}{c}\text { Control } \\
\text { Electronics }\end{array}$ & $\begin{array}{c}\text { Integrity/Degradation } \\
\text { Evaluation }\end{array}$ & Thermal Increment & $\begin{array}{l}\text { Thermal } \\
\text { Sensing }\end{array}$ & $\begin{array}{c}\text { Electrical } \\
\text { Recording }\end{array}$ & $\begin{array}{l}\text { Substrate } \\
\text { Material }\end{array}$ \\
\hline$[45] / 2013$ & $\begin{array}{l}\text { Shaft: } 12 \mathrm{~mm} \text {; Width(W): } 900 \mu \mathrm{m} ; \mu \text { LED: } \\
1000 \times 600 \times 200 \mu \mathrm{m}^{3}\end{array}$ & 1 & $\begin{array}{c}0.7 \\
\mathrm{~mW} / \mathrm{mm}^{2}\end{array}$ & $\begin{array}{l}\text { Power: } \\
14.5 \mathrm{~mW}\end{array}$ & $\begin{array}{l}\text { External } \\
\text { instruments }\end{array}$ & No & - & No & Yes & Polyimide \\
\hline$[46] / 2014$ & $\begin{array}{l}\text { length(L): } 4.2 \mathrm{~mm} \text {; W: } 0.86 \mathrm{~mm} ; \mu \mathrm{LED}: \\
\quad 550 \times 600 \times 200 \mu^{3}\end{array}$ & 1 & $\begin{array}{c}0.95 \\
\mathrm{~mW} / \mathrm{mm}^{2}\end{array}$ & $\begin{array}{l}\text { Power: } \\
>216 \mathrm{~mW}\end{array}$ & - & No & $\begin{array}{l}0.5^{\circ} \mathrm{C} \text { increase with } 7 \mathrm{~mW} \\
\text { power and } 2.74 \mathrm{~V} \text { input voltage }\end{array}$ & No & No & SU-8 \\
\hline$[47,48] / 2016$ & $\begin{array}{l}\text { Shank L: } 5 \mathrm{~mm} \text {; W: } 0.9 \mathrm{~mm} ; \\
\mu \text { LED: } 550 \times 600 \times 200 \mu \mathrm{m}^{3}\end{array}$ & 1 & $\begin{array}{c}1.5 \\
\mathrm{~mW} / \mathrm{mm}^{2}\end{array}$ & $\begin{array}{l}\text { Voltage: } \\
3.6 \mathrm{~V}\end{array}$ & $\begin{array}{c}\text { External } \\
\text { instruments }\end{array}$ & No & $\begin{array}{l}1{ }^{\circ} \mathrm{C} \text { increase with } \\
3.6 \mathrm{~V} \text { input voltage }\end{array}$ & No & Yes & $\begin{array}{l}\text { Polycrystalline } \\
\text { Diamond }\end{array}$ \\
\hline$[50] / 2013$ & $\begin{array}{c}\text { L: } 7 \text { mm; Shaft L: } 1 \text { mm; W: } 80 \mu \mathrm{m} \text {; } \\
\text { } \text { LED: } 40 \mu \mathrm{m} \text { diameter }\end{array}$ & 5 & $\begin{array}{c}600 \\
\mathrm{~mW} / \mathrm{mm}^{2}\end{array}$ & - & $\begin{array}{c}\text { External } \\
\text { instruments }\end{array}$ & No & $\begin{array}{l}1.5^{\circ} \mathrm{C} \text { increase with } 600 \\
\mathrm{~mW} / \mathrm{mm}^{2} \text { and } 200 \mathrm{~ms} \text { pulse }\end{array}$ & No & No & Sapphire \\
\hline$[51] / 2016$ & $\begin{array}{l}\text { Total L: } 3 \mathrm{~mm} \text {; Shaft L: } 750 \mu \mathrm{m} \text {; } \\
\quad \mu \mathrm{LED}: 25 \mu \mathrm{m} \text { diameter }\end{array}$ & 16 & $\begin{array}{c}400 \\
\mathrm{~mW} / \mathrm{mm}^{2}\end{array}$ & $\begin{array}{l}\text { Current: } \\
5 \mathrm{~mA}\end{array}$ & $\begin{array}{l}\text { External } \\
\text { PCB control } \\
\text { boards }\end{array}$ & No & $\begin{array}{c}0.5^{\circ} \mathrm{C} \text { increase with } \\
150 \mathrm{~mW} / \mathrm{mm}^{2} \text { radiance and } \\
50 \mathrm{~ms} \text { pulse; Max: } 4^{\circ} \mathrm{C}\end{array}$ & No & No & Silicon \\
\hline$[52] / 2015$ & $\begin{array}{l}\text { Shank L: } 5 \mathrm{~mm} ; \mathrm{W}: 70 \mu \mathrm{m} ; \\
\quad \mu \mathrm{LED}: 11 \times 13 \mu \mathrm{m}^{2}\end{array}$ & $3 \times 4$ & $\begin{array}{c}353 \\
\mathrm{~mW} / \mathrm{mm}^{2}\end{array}$ & $\begin{array}{l}\text { Current: } \\
5 \mathrm{~mA}\end{array}$ & $\begin{array}{l}\text { External } \\
\text { PCB control } \\
\text { boards }\end{array}$ & No & $\begin{array}{l}<1.0^{\circ} \mathrm{C} \text { increase with } \\
3.4 \mathrm{~V} \text { voltage }\end{array}$ & No & Yes & Silicon \\
\hline$[53] / 2013$ & $\begin{array}{l}\text { Shaft L: } 1 \mathrm{~mm} ; \mathrm{W}: \sim 400 \mu \mathrm{m} \text {; Thickness: } \\
\sim 20 \mu \mathrm{m} \text {; LED dimensions: } 50 \times 50 \mu \mathrm{m}^{2}\end{array}$ & 4 & $\begin{array}{c}\sim 40 \\
\mathrm{~mW} / \mathrm{mm}^{2}\end{array}$ & $\begin{array}{l}\text { Power: } \\
40 \mathrm{~mW}\end{array}$ & $\begin{array}{c}\text { External } \\
\text { flexible/rigid } \\
\text { control } \\
\text { boards }\end{array}$ & No & $\begin{array}{c}1.0^{\circ} \mathrm{C} \text { with } 17.7 \mathrm{~mW} / \mathrm{mm}^{2} \\
\text { radiance and } 10 \mathrm{~ms} \text { pulse; } \\
\text { Max: } 10^{\circ} \mathrm{C}\end{array}$ & Yes & Yes & $\begin{array}{l}\text { Platinum, } \\
\text { Silicon, } \\
\text { Polymer }\end{array}$ \\
\hline [54-56]/2017 & $\begin{array}{l}\text { Shaft L: } 4400 \mu \mathrm{m} ; \mathrm{W}: 200 \mu \mathrm{m} \\
\mu \mathrm{LED} \text { dimensions: } 20 \mu \mathrm{m} \times 20 \mu \mathrm{m}^{2}\end{array}$ & $6-18$ & $\begin{array}{c}1256 \\
\mathrm{~mW} / \mathrm{mm}^{2}\end{array}$ & $\begin{array}{l}\text { Power: } \\
6.04 \mathrm{~mW}\end{array}$ & $\begin{array}{l}\text { In-built } \\
\text { active } \\
\text { electronics }\end{array}$ & Yes & $0.8^{\circ} \mathrm{C}$ with $6 \mathrm{~mW}$ power & Yes & Yes & Silicon \\
\hline
\end{tabular}




\section{Discussion}

This paper has reviewed recently published work on optogenetic implants. Wave-guiding structure and $\mu \mathrm{LED}$-on-optrode structure have both been investigated. The limitations of each reviewed device have also been identified. Following this, several observations are presented below.

\subsection{Light Delivery Stability and Precision}

For implantable optical stimulation, stable light delivery is demanded. Laser sources provide coherent light emission with low divergence, and $\mu$ LEDs achieve more stable light delivery [28-30]. One concern of the wave-guiding structure is its low coupling efficiency with both lasers and LEDs [27]. Another concern is that, due to their bulky dimensions, the multiplexing of wave-guiding structures for multi-site stimulation is challenging. In recent years, vertical-cavity surface-emitting laser (VSCEL) demonstrates several merits over conventional lasers and $\mu$ LEDs: low power consumption, narrow bandwidth, and high efficiency $[57,58]$. Blue-light VSCELs may be an optimal choice as emitters in optogenetic implants when they become commercially available in the future.

\subsection{Optrode Dimensions}

The optrode dimensions must be miniature. Several of the existing devices are comparatively large which may not be suitable for implantable animal experiments. The length of optrode shaft should be around $4 \mathrm{~mm}$, achieving implant miniaturisation and matching the cortex thickness [49]. The shafts of some of the optical probes reviewed above are relatively short (around $1 \mathrm{~mm}$ or even shorter), which would make them unusable for deeper multi-layer stimulation. Optrode width and thickness (or diameter) should be within micrometre scale, minimising the potential tissue damage caused by device insertions. The head part of the implant should be of small dimensions and lightweight. The probe heads of several existing devices occupy large spaces, which may cause an extra burden for experimental subjects. Also, light emitters should be designed with minimal dimensions. This will help to increase luminance intensity, and facilitate multi-site stimulation, and also further minimise the implant.

\subsection{Spatial Resolution and Temporal Resolution}

The implant should be applicable to extensive brain network to allow the analysis of complex neural circuitry. In 2014, Shulyzki et al. [59] has developed a microchip based Utah-type probe to achieve 256 electrical recording sites along with 64 electrical stimulation sites. More interesting work have been demonstrated by Lopez et al. [60] and Angotzi et al. [61] to accomplish high-density neural probes. Likewise, optogenetic implants should hold appropriate spatial resolution (in the micrometre scale) for multi-site and multi-layer stimulation. Besides this, although the pulse frequency of stimulation operation is fairly low (typically less than $1 \mathrm{kHz}$ ), it is desirable to realise relatively high temporal resolution so as to improve the stimulation accuracy and efficiency.

\subsection{Intensity Controllability}

Light intensity controlling presently relies on manually changing the stimulation pulse width and/or shifting the driving current/voltage. It is desired and important to incorporate a more advanced control mechanism so as to achieve finer overall intensity modulation. This would be meaningful for optimising light/power efficiency, enhancing stimulation precision, improving operational safety, and regulating temperature increases [50,54,55]. Additionally, high-intensity emission is required, especially for deeper penetration applications.

\subsection{Intelligent Implantable Electronics}

To date, except [54-56], all of the existing optogenetic implants are passively controlled by different external controlling devices. This might increase the development complexity of the 
implantable system. Different implants require diverse dedicated controlling equipment, which might be cost-ineffective and labour-intensive. More importantly, these external controlling devices are not entirely compatible with those implants developed by other researchers. This would limit their broader applications. Besides, the relatively bulky dimensions and high power consumption of these controlling systems may further restrict the adoption of the implants in freely-moving animal experiments and/or clinical applications. Thus, there is an increasing need to construct an intelligent optogenetic implant for actual medical utilisations. Active controlling electronics should be built inside of the implant, which should be able to actively perform all required operations as a smart system. Standard communication protocol (such as Serial Peripheral Interface, SPI) should be embedded into the device, and moreover, this active implant should be compatible with general biomedical microcontrollers, so as to be easily adopted by the wider research communities and society.

\subsection{Integrity and Degradation Evaluation}

As the implant would be inserted into the brain, it will be difficult for clinical staffs / patients to observe its real-time working status. In particular, any breakage or component failure occurring in the implant may lead to high risks to patients' health. Some preliminary analyses have been conducted in commercially available single-LED optrode [62]. However, in this review except [54-56], none of the studies published so far include a relevant evaluation strategy created within the implants. Thus, it would be advantageous to incorporate a dedicated sensing scheme for the evaluation of the system integrity and long-term durability.

\subsection{Thermal Effect}

Heat dissipation is of crucial importance in any optical implant, especially for the

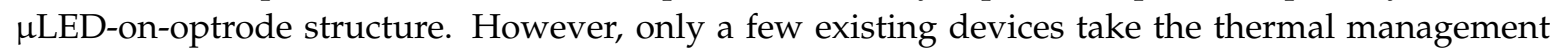
into account. Detailed thermal analyses is essential to be conducted for proposed optrodes, and it is necessary to restrict temperature increases by a reasonable boundary (ideally within $2{ }^{\circ} \mathrm{C}$ [63-65]). Moreover, it is desirable for temperature sensors to be incorporated, which can monitor the system thermal effects in real-time. This will benefit both system stability and tissue health.

\subsection{Neural Recording Function}

The use of a closed-loop neural interface is a growing trend in neuroprosthesis applications. The majority of current optogenetic implants are still conventional open-loop systems. For a new type of optogenetic implants, neural recording components should be built in. Local neural activities could then be observed to provide in situ feedback signals for stimulation operation. This could improve the system functioning performance, operational efficiency, and power efficiency.

However, when performing optical stimulation and electrical recording simultaneously, light-induced artefacts could be generated [66], and this usually caused by a photoelectric artefact called Becquerel effect [67]. This effect is challenging to be prevented and could potentially contaminate the electrical neural recording signals. One way is to utilise incoherent light source to reduce the Becquerel effect [67]. An alternative approach is to use transparent materials to construct recording electrodes to eliminate photoelectric artefact. Another method is to minimise the dimensions of recording electrodes to weaken the Becquerel effect [67]. However, either way cannot completely eliminate the photoelectric artefact. Other possible approaches should be continuously explored in the future.

To achieve the closed-loop integration, specific sophisticated closed-loop algorithm (such as spike classification, threshold detection) should be embedded into the control unit (e.g., PC, chest $\mu$ controller) of the system. However, in the process of compiling this review, it is surprisingly common for this key characteristic to be omitted from most of reviewed literatures. The author thus suggests that reasonable description of algorithm implementation should be provided in the peer-reviewed closed-loop optogenetic implants in the future. 


\subsection{Fabrication Technology}

Most existing optogenetic implants are custom-fabricated, which might be comparatively costly and labour-intensive. This may also create a barrier for widespread adoption and application. Thus, it is demanding to construct optogenetic implants using a commercially available fabrication process. One optimal choice is to utilise commercially available CMOS fabrication process. Lopez et al. [60], Angotzi et al. [61] and Shulyzki et al. [59] proposed active CMOS electronics for electrical recording/stimulation, and these works demonstrated the feasibility to utilise the probe shaft for active electronics. However, none of them is optoelectronic probes for the field of optogenetics. Then Zhao et al. [54-56] first proposed an active optrode for optogenetic stimulation with similar fabrication process with that of Lopez et al. [60], Angotzi et al. [61] and Shulyzki et al. [59]. To our knowledge, the work presented by Zhao et al. [54-56] is the first CMOS-based active optogenetic implant. This may open a new door for development of miniaturized optogenetic implant.

\subsection{Power Consumption}

Power consumption is also important for implantable applications, and it is critical for both battery operation and wireless power transmission. Most existing devices require strong current/high voltage, or their designs have not taken the power budget into consideration. It could be meaningful to optimise the system power consumption using low power design strategies such as power gating, energy harvesting, etc.

\subsection{Substrate Materials}

Variable materials have been utilised in these optogenetic implants as substrates. Polymer can demonstrate outstanding flexibility, but its high hygroscopicity may bias the long-term optical performance of the device. Diamond/sapphire materials have also been explored for probe constructions. These materials can provide finer thermal conductivity, but their strong mechanical rigidity may cause severe tissue damage and subsequent infections. Recently, silicon has also been utilised for substrate materials. Silicon can be potentially compatible with commercial CMOS process, however, its frangibility is a concern for long-term use. Thus, an "ideal" substrate materials should demonstrate good thermal conductivity, biocompatibility, robustness and flexibility, and should be easy for fabrication. This will require continuous efforts from materials and fabrication specialists to further push the technology forward.

\section{Conclusions}

To conclude, various fabrication technologies have been investigated and utilised for the development of optogenetic implants. Although these existing devices can meet the need of optogenetic stimulation to some extent, they have some areas for enhancement, in terms of illuminance stability, multi-site operation, intensity controllability, and miniaturisation. Moreover, it is desirable to incorporate different sensing and evaluation schemes into the implant. This could highly improve the overall system performance, with regard to safety, reliability, operation efficiency and functioning accuracy. Thermal sensing components, neural recording electronics, and integrity and functioning evaluation schemes should be built into the implant. More importantly, the targeted implant should be actively driven, acting as an intelligent standalone system. This intelligent implant should be fully compatible with conventional biomedical microprocessors, which can be widely unitised in the broader biomedical engineering field. In addition, the targeted implantable device is expected to be fabricated using a commercially available technology, which would be more convenient for other researchers to adopt.

Optogenetics possesses great potential for treating neurological disorders. By photosensitising neurons via particular opsins, this method can be fully utilised for the investigation of complicated brain networks and neurological diseases. Potential applications are Parkinson's disease, epilepsy, 
blindness, and other conditions. One of the key challenges is to construct appropriate optogenetic implants to deliver local light into the brain tissue of interest. This requires multidisciplinary effort from optical-electronics, biocompatible materials, precise fabrication, stable packaging, neuroscience and biology. The next five to ten years appears to be an exciting period for the development of new-generation optogenetic implants. It can be foreseen that multifunctional (optical stimulation, electrical recording, temperature sensing, etc.) intelligent device will be the trend of next-generation optogenetic implantable devices.

Conflicts of Interest: The author declares no conflicts of interest.

\section{References}

1. Fork, R.L. Laser Stimulation of Nerve Cells in Aplysia. Science 1971, 171, 907-908. [CrossRef] [PubMed]

2. Crick, F. The impact of molecular biology on neuroscience. Philos. Trans. R. Soc. B Biol. Sci. 1999, 354, 2021-2025. [CrossRef] [PubMed]

3. Lima, S.Q.; Miesenböck, G. Remote Control of Behavior through Genetically Targeted Photostimulation of Neurons. Cell 2005, 121, 141-152. [CrossRef] [PubMed]

4. Callaway, E.M.; Katz, L.C. Photostimulation using caged glutamate reveals functional circuitry in living brain slices. Proc. Natl. Acad. Sci. USA 1993, 90, 7661-7665. [CrossRef] [PubMed]

5. Volgraf, M.; Gorostiza, P.; Numano, R.; Kramer, R.H.; Isacoff, E.Y.; Trauner, D. Allosteric control of an ionotropic glutamate receptor with an optical switch. Nat. Chem. Biol. 2006, 2, 47-52. [CrossRef] [PubMed]

6. Szobota, S.; Gorostiza, P.; Del Bene, F.; Wyart, C.; Fortin, D.L.; Kolstad, K.D.; Tulyathan, O.; Volgraf, M.; Numano, R.; Aaron, H.L.; et al. Remote Control of Neuronal Activity with a Light-Gated Glutamate Receptor. Neuron 2007, 54, 535-545. [CrossRef] [PubMed]

7. Zemelman, B.V.; Lee, G.A.; Ng, M.; Miesenböck, G. Selective Photostimulation of Genetically ChARGed Neurons. Neuron 2002, 33, 15-22. [CrossRef]

8. Zemelman, B.V.; Nesnas, N.; Lee, G.A.; Miesenböck, G. Photochemical gating of heterologous ion channels: Remote control over genetically designated populations of neurons. Proc. Natl. Acad. Sci. USA 2003, 100, 1352-1357. [CrossRef] [PubMed]

9. Kravitz, A.V.; Kreitzer, A.C. Optogenetic Manipulation of Neural Circuitry In Vivo. Curr. Opin. Neurobiol. 2011, 21, 433-439. [CrossRef] [PubMed]

10. Nagel, G.; Szellas, T.; Huhn, W.; Kateriya, S.; Adeishvili, N.; Berthold, P.; Ollig, D.; Hegemann, P.; Bamberg, E. Channelrhodopsin-2, a directly light-gated cation-selective membrane channel. Proc. Natl. Acad. Sci. USA 2003, 100, 13940-13945. [CrossRef] [PubMed]

11. Boyden, E.S.; Zhang, F.; Bamberg, E.; Nagel, G.; Deisseroth, K. Millisecond-timescale, genetically targeted optical control of neural activity. Nat. Neurosci. 2005, 8, 1263-1268. [CrossRef] [PubMed]

12. Li, X.; Gutierrez, D.V.; Hanson, M.G.; Han, J.; Mark, M.D.; Chiel, H.; Hegemann, P.; Landmesser, L.T.; Herlitze, S. Fast noninvasive activation and inhibition of neural and network activity by vertebrate rhodopsin and green algae channelrhodopsin. Proc. Natl. Acad. Sci. USA 2005, 102, 17816-17821. [CrossRef] [PubMed]

13. Nagel, G.; Brauner, M.; Liewald, J.F.; Adeishvili, N.; Bamberg, E.; Gottschalk, A. Light Activation of Channelrhodopsin-2 in Excitable Cells of Caenorhabditis elegans Triggers Rapid Behavioral Responses. Curr. Biol. 2005, 15, 2279-2284. [CrossRef] [PubMed]

14. Schroll, C.; Riemensperger, T.; Bucher, D.; Ehmer, J.; Völler, T.; Erbguth, K.; Gerber, B.; Hendel, T.; Nagel, G.; Buchner, E.; et al. Light-Induced Activation of Distinct Modulatory Neurons Triggers Appetitive or Aversive Learning in Drosophila Larvae. Curr. Biol. 2006, 16, 1741-1747. [CrossRef] [PubMed]

15. Petreanu, L.; Huber, D.; Sobczyk, A.; Svoboda, K. Channelrhodopsin-2-assisted circuit mapping of long-range callosal projections. Nat. Neurosci. 2007, 10, 663-668. [CrossRef] [PubMed]

16. Arenkiel, B.R.; Peca, J.; Davison, I.G.; Feliciano, C.; Deisseroth, K.; Augustine, G.J.; Ehlers, M.D.; Feng, G. In Vivo Light-Induced Activation of Neural Circuitry in Transgenic Mice Expressing Channelrhodopsin-2. Neuron 2007, 54, 205-218. [CrossRef] [PubMed]

17. Alexander, M.A.; Li-Ping, W.; Feng, Z.; Leslie, A.M.; Murtaza, Z.M.; Schneider, M.B.; Karl, D. An optical neural interface: In vivo control of rodent motor cortex with integrated fiberoptic and optogenetic technology. J. Neural Eng. 2007, 4, S143. 
18. Zhang, F.; Wang, L.-P.; Brauner, M.; Liewald, J.F.; Kay, K.; Watzke, N.; Wood, P.G.; Bamberg, E.; Nagel, G.; Gottschalk, A.; et al. Multimodal fast optical interrogation of neural circuitry. Nature 2007, 446, 633-639. [CrossRef] [PubMed]

19. Gradinaru, V.; Thompson, K.R.; Deisseroth, K. eNpHR: A Natronomonas halorhodopsin enhanced for optogenetic applications. Brain Cell Biol. 2008, 36, 129-139. [CrossRef] [PubMed]

20. Barrett, J.M. Information Transmission in Normal Vision and Optogenetically Resensitised Dystrophic Retinas; Newcastle University: Newcastle upon Tyne, UK, 2015.

21. Mohanty, S.K.; Lakshminarayananan, V. Optical Techniques in Optogenetics. J. Mod. Opt. 2015, 62, 949-970. [CrossRef] [PubMed]

22. Lin, J.Y. A User's Guide to Channelrhodopsin Variants: Features, Limitations and Future Developments. Exp. Physiol. 2011, 96, 19-25. [CrossRef] [PubMed]

23. Dawydow, A.; Gueta, R.; Ljaschenko, D.; Ullrich, S.; Hermann, M.; Ehmann, N.; Gao, S.; Fiala, A.; Langenhan, T.; Nagel, G.; et al. Channelrhodopsin-2-XXL, a powerful optogenetic tool for low-light applications. Proc. Natl. Acad. Sci. USA 2014, 111, 13972-13977. [CrossRef] [PubMed]

24. Gradinaru, V.; Mogri, M.; Thompson, K.R.; Henderson, J.M.; Deisseroth, K. Optical Deconstruction of Parkinsonian Neural Circuitry. Science 2009, 324, 354. [CrossRef] [PubMed]

25. Krook-Magnuson, E.; Armstrong, C.; Oijala, M.; Soltesz, I. On-demand optogenetic control of spontaneous seizures in temporal lobe epilepsy. Nat. Commun. 2013, 4, 1376. [CrossRef] [PubMed]

26. RetroSense Therapeutics Granted Orphan Drug Designation for Lead Product RST-001 for Retinitis Pigmentosa. Available online: http://www.businesswire.com/news/home/20141030005642/en/ RetroSense-Therapeutics-Granted-Orphan-Drug-Designation-Lead\%20-\%20.VFLocihTRK4 (accessed on 30 October 2014).

27. Lecture 4: Optical Waveguides. Available online: http:/ / course.ee.ust.hk/elec509/notes/Lect4-Optical\% 20waveguides.pdf (accessed on 6 July 2013).

28. Fan, B.; Li, W. Miniaturized optogenetic neural implants: A review. Lab Chip 2015, 15, 3838-3855. [CrossRef] [PubMed]

29. Warden, M.R.; Cardin, J.A.; Deisseroth, K. Optical Neural Interfaces. Annu. Rev. Biomed. Eng. 2014, 16, 103-129. [CrossRef] [PubMed]

30. Pashaie, R.; Anikeeva, P.; Lee, J.H.; Prakash, R.; Yizhar, O.; Prigge, M.; Chander, D.; Richner, T.J.; Williams, J. Optogenetic Brain Interfaces. IEEE Rev. Biomed. Eng. 2014, 7, 3-30. [CrossRef] [PubMed]

31. LeChasseur, Y.; Dufour, S.; Lavertu, G.; Bories, C.; Deschenes, M.; Vallee, R.; De Koninck, Y. A microprobe for parallel optical and electrical recordings from single neurons in vivo. Nat. Methods 2011, 8, 319-325. [CrossRef] [PubMed]

32. Dufour, S.; Lavertu, G.; Dufour-Beauséjour, S.; Juneau-Fecteau, A.; Calakos, N.; Deschênes, M.; Vallée, R.; De Koninck, Y. A Multimodal Micro-Optrode Combining Field and Single Unit Recording, Multispectral Detection and Photolabeling Capabilities. PLoS ONE 2013, 8, e57703. [CrossRef] [PubMed]

33. Zorzos, A.N.; Scholvin, J.; Boyden, E.S.; Fonstad, C.G. Three-dimensional multiwaveguide probe array for light delivery to distributed brain circuits. Opt. Lett. 2012, 37, 4841-4843. [CrossRef] [PubMed]

34. Jing, W.; Fabien, W.; David, A.B.; Jiayi, Z.; Ilker, O.; Rebecca, D.B.; Arto, V.N.; Rick van, W.; Ilka, D.; Karl, D. Integrated device for combined optical neuromodulation and electrical recording for chronic in vivo applications. J. Neural Eng. 2012, 9, 016001.

35. Schwaerzle, M.; Paul, O.; Ruther, P. Compact silicon-based optrode with integrated laser diode chips, SU-8 waveguides and platinum electrodes for optogenetic applications. J. Micromech. Microeng. 2017, 27, 065004. [CrossRef]

36. Schwaerzle, M.; Ringwald, P.; Paul, O.; Rüther, P. First dual-color optrode with bare laser diode chips directly butt-coupled to hybrid-polymer waveguides. In Proceedings of the 2017 IEEE 30th International Conference on Micro Electro Mechanical Systems (MEMS), Las Vegas, NV, USA, 22-26 January 2017; pp. 526-529.

37. Mohanty, S.K.; Thakor, N.V. Front Matter: Volume 8586. In Proceedings Volume 8586 Optogenetics: Optical Methods for Cellular Control; SPIE: Bellingham, WA, USA, 2013.

38. Stark, E.; Koos, T.; Buzsaki, G. Diode-probes for spatiotemporal optical control of multiple neurons in freely-moving animals. J. Neurophysiol. 2012, 108, 349-363. [CrossRef] [PubMed] 
39. Schwaerzle, M.; Elmlinger, P.; Paul, O.; Ruther, P. Miniaturized tool for optogenetics based on an LED and an optical fiber interfaced by a silicon housing. In Proceedings of the 2014 36th Annual International Conference of the IEEE Engineering in Medicine and Biology Society, Chicago, IL, USA, 26-30 August 2014; pp. 5252-5255.

40. Schwaerzle, M.; Elmlinger, P.; Paul, O.; Ruther, P. Miniaturized $3 \times 3$ optical fiber array for optogenetics with integrated $460 \mathrm{~nm}$ light sources and flexible electrical interconnection. In Proceedings of the 2015 28th IEEE International Conference on Micro Electro Mechanical Systems (MEMS), Estoril, Portugal, 18-22 January 2015; pp. 162-165.

41. Rubehn, B.; Wolff, S.B.E.; Tovote, P.; Schuettler, M.; Lüthi, A.; Stieglitz, T. Polymer-based shaft microelectrodes with optical and fluidic capabilities as a tool for optogenetics. In Proceedings of the 2011 Annual International Conference of the IEEE Engineering in Medicine and Biology Society, Boston, MA, USA, 30 August-3 September 2011; pp. 2969-2972.

42. Wu, F.; Stark, E.; Im, M.; Cho, I.-J.; Yoon, E.-S.; Buzsáki, G.; Wise, K.D.; Yoon, E. An implantable neural probe with monolithically integrated dielectric waveguide and recording electrodes for optogenetics applications. J. Neural Eng. 2013, 10, 056012. [CrossRef] [PubMed]

43. Son, Y.; Lee, H.J.; Kim, J.; Lee, C.J.; Yoon, E.S.; Kim, T.G.; Cho, I.J. A new monolithically integrated multi-functional MEMS neural probe for optical stimulation and drug delivery. In Proceedings of the 2015 28th IEEE International Conference on Micro Electro Mechanical Systems (MEMS), Estoril, Portugal, 18-22 January 2015; pp. 158-161.

44. Keiser, G. Optical Fiber Communications; McGraw-Hill Education (India) Pvt Limited: Bengaluru, India, 2008; p. 580.

45. Cao, H.; Gu, L.; Mohanty, S.K.; Chiao, J.C. An Integrated $\mu$ LED Optrode for Optogenetic Stimulation and Electrical Recording. IEEE Trans. Biomed. Eng. 2013, 60, 225-229. [CrossRef] [PubMed]

46. Fan, B.; Kwon, K.Y.; Weber, A.J.; Li, W. An implantable, miniaturized SU-8 optical probe for optogenetics-based deep brain stimulation. In Proceedings of the 2014 36th Annual International Conference of the IEEE Engineering in Medicine and Biology Society, Chicago, IL, USA, 26-30 August 2014; pp. 450-453.

47. Fan, B.; Kwon, K.-Y.; Rechenberg, R.; Becker, M.F.; Weber, A.J.; Li, W. A hybrid neural interface optrode with a polycrystalline diamond heat spreader for optogenetics. Technology 2016, 4, 15-22. [CrossRef]

48. Fan, B.; Kwon, K.Y.; Rechenberg, R.; Khomenko, A.; Haq, M.; Becker, M.F.; Weber, A.J.; Li, W. A polycrystalline diamond-based, hybrid neural interfacing probe for optogenetics. In Proceedings of the 2015 28th IEEE International Conference on Micro Electro Mechanical Systems (MEMS), Estoril, Portugal, 18-22 January 2015; pp. 616-619.

49. Fischl, B.; Dale, A.M. Measuring the thickness of the human cerebral cortex from magnetic resonance images. Proc. Natl. Acad. Sci. USA 2000, 97, 11050-11055. [CrossRef] [PubMed]

50. McAlinden, N.; Massoubre, D.; Richardson, E.; Gu, E.; Sakata, S.; Dawson, M.D.; Mathieson, K. Thermal and optical characterization of micro-LED probes for in vivo optogenetic neural stimulation. Opt. Lett. 2013, 38, 992-994. [CrossRef] [PubMed]

51. Scharf, R.; Tsunematsu, T.; McAlinden, N.; Dawson, M.D.; Sakata, S.; Mathieson, K. Depth-specific optogenetic control in vivo with a scalable, high-density $\mu$ LED neural probe. Sci. Rep. 2016, 6. [CrossRef] [PubMed]

52. Wu, F.; Stark, E.; Ku, P.-C.; Wise, K.D.; Buzsáki, G.; Yoon, E. Monolithically Integrated $\mu$ LED on Silicon Neural Probes for High-Resolution Optogenetic Studies in Behaving Animals. Neuron 2015, 88, 1136-1148. [CrossRef] [PubMed]

53. Kim, T.-I.; McCall, J.G.; Jung, Y.H.; Huang, X.; Siuda, E.R.; Li, Y.; Song, J.; Song, Y.M.; Pao, H.A.; Kim, R.-H.; et al. Injectable, Cellular-Scale Optoelectronics with Applications for Wireless Optogenetics. Science 2013, 340, 211-216. [CrossRef] [PubMed]

54. Zhao, H. Self-Diagnosis Implantable Optrode for Optogenetic Stimulation. Ph.D. Thesis, Newcastle University, Newcastle upon Tyne, UK, 2017.

55. Zhao, H.; Dehkhoda, F.; Ramezani, R.; Sokolov, D.; Degenaar, P.; Liu, Y.; Constandinou, T. A CMOS-based neural implantable optrode for optogenetic stimulation and electrical recording. In Proceedings of the 2015 IEEE Biomedical Circuits and Systems Conference (BioCAS), Atlanta, GA, USA, 22-24 October 2015; pp. 1-4. 
56. Zhao, H.; Sokolov, D.; Degenaar, P. An implantable optrode with Self-diagnostic function in $0.35 \mu \mathrm{m}$ CMOS for optical neural stimulation. In Proceedings of the 2014 IEEE Biomedical Circuits and Systems Conference (BioCAS) Proceedings, Lausanne, Switzerland, 22-24 October 2014; pp. 244-247.

57. Johnson, K.; Dummer, M.; Hibbs-Brenner, M.; Hogan, W.; Steidl, C. Progress in extended wavelength VCSEL technology. Proc. SPIE 2013, 8639, 863905.

58. Downing, J.; Babić, D.; Hibbs-Brenner, M. An ultra-stable VCSEL light source. Proc. SPIE 2013, 8639, 86390B.

59. Shulyzki, R.; Abdelhalim, K.; Bagheri, A.; Salam, M.T.; Florez, C.M.; Velazquez, J.L.P.; Carlen, P.L.; Genov, R. 320-Channel Active Probe for High-Resolution Neuromonitoring and Responsive Neurostimulation. IEEE Trans. Biomed. Circuits Syst. 2015, 9, 34-49. [CrossRef] [PubMed]

60. Lopez, C.M.; Andrei, A.; Mitra, S.; Welkenhuysen, M.; Eberle, W.; Bartic, C.; Puers, R.; Yazicioglu, R.F.; Gielen, G.G.E. An Implantable 455-Active-Electrode 52-Channel CMOS Neural Probe. IEEE J. Solid State Circuits 2014, 49, 248-261. [CrossRef]

61. Angotzi, G.N.; Malerba, M.; Zucca, S.; Berdondini, L. A 512-channels, whole array readout, CMOS implantable probe for acute recordings from the brain. In Proceedings of the 2015 37th Annual International Conference of the IEEE Engineering in Medicine and Biology Society (EMBC), Milan, Italy, 25-29 August 2015; pp. 877-880.

62. Multichannel Systems TBSI-LED-211-N. Available online: http:/ / www.multichannelsystems.com/products / tbsi-led-211-n (accessed on 16 June 2017).

63. IEEE. IEEE Standard for Safety Levels with Respect to Human Exposure to Radio Frequency Electromagnetic Fields, $3 \mathrm{kHz}$ to $300 \mathrm{GHz}$; IEEE: Piscataway, NJ, USA, 2006; pp. 1-238.

64. Agency, H.P. Health Effects from Radiofrequency Electromagnetic Fields; National Radiological Protection Board (NRPB): London, UK, 2012.

65. Borton, D.A.; Yin, M.; Aceros, J.; Nurmikko, A. An Implantable Wireless Neural Interface for Recording Cortical Circuit Dynamics in Moving Primates. J. Neural Eng. 2013, 10, 026010. [CrossRef] [PubMed]

66. Cardin, J.A.; Carlen, M.; Meletis, K.; Knoblich, U.; Zhang, F.; Deisseroth, K.; Tsai, L.-H.; Moore, C.I. Driving fast-spiking cells induces gamma rhythm and controls sensory responses. Nature 2009, 459, 663-667. [CrossRef] [PubMed]

67. Kozai, T.D.Y.; Vazquez, A.L. Photoelectric artefact from optogenetics and imaging on microelectrodes and bioelectronics: New challenges and opportunities. J. Mater. Chem. B 2015, 3, 4965-4978. [CrossRef] [PubMed] 